\title{
Assessment health care services among health care workers in holy Karbala governorate
}

\author{
Ali Neamah Hasan Al-Aaragi ${ }^{1}$, Mohammed Abdulridha Merzah², Ali Abd Al-Latif G. Mohammed ${ }^{3}$ \\ Department of Community Health, Technical Institute of Karbala, Al-Furat Al-Awsat Technical University, \\ Kufa, Iraq
}

\begin{abstract}
Background: Objective: Objectives of the study were to 1) Figuring out the degree of utilization for the beneficiary health users, together with overall and detailed provider's satisfaction with primary health care services provided. 2) Suggesting a renovate plan for Iraqi health system reform. Subjects and Methods: A cross sectional survey was conduct in Health Directorate of Holy Karbala Governorate, Iraq . A total 572 of health providers a self-administered questionnaire on factors associated with job satisfaction, Were included in this study. The data collection carried out for a period of five months from January 2, 2017 to the end of May 2017. Data collected by direct interview with health providers using a questionnaire form that designed based on the study objectives, it administered to the participants and the results consolidated and tested for any statistical significance. Results: Total sample in this study were 572 health providers $(65.4 \%$ male and $34.6 \%$ female), the mean age of the study population was $36.8 \pm 9.8$ years, The study population was the age range at the time of study were between (21-60) years, (male: female ratio was 1.3:1) and the highest percentage $(35.7 \%)$ were in the age group $(\leq 30)$ years. The most of the respondents were lived in urban areas as represent $(58.7 \%)$. Regarding the distribution of health providers as educational level about half of studied sample (49.7 $\%)$ from College and more, while regarding health title more than half of studied sample $(57.9 \%)$ were Paramedical staff. Regarding afternoon work (56.0\%) of health providers have an afternoon work, $(67.0 \%)$ agree with health insurance and having a family doctor for each area responsible for family members' health, while (43.0\%) agree with prevent mix of private and governmental work. Conclusion: The overall scores were acceptable regarding assessment of health provider's among health care services in primary health care centers, and conduct of health assurance program in the health system of Iraq. A better educational program on health assurance program should conducted to improve awareness, attitude, and practice toward health assurance program using mass media and health education in all Ministries and community. Statistical analysis: Data input to computer file for storage and Analysis Statistical package for the social sciences (SPSS) version 18 used for data description and analysis, Descriptive statistic included the use of frequencies and percentages. The Chi-Square statistical test used to test for associations between variables with the results considered as statistically significant when the $P$ value was equal or less than 0.05
\end{abstract}

Keywords: health care services, primary health care centers, health providers, health assurance program.

DOI: $10.7176 / \mathrm{JBAH} / 9-10-13$

Publication date:May 31st 2019

\section{INTRODUCTION}

Job satisfaction had varies definition from person to person also even for person from time to time. And an evaluation of the job and the environment surrounding the job by the employee [1] . in general It is also can be defined as employee feelings about has the job [2]. Generally, job satisfaction can be defined as the difference between the amount of rewards workers receive and the amount they believe they should receive [3]. The job satisfaction of the primary health care workers (PHCWs) is a critical factor for health systems, because the primary care level is dependable for affording medical and health care to a larger proportion of the population than any other care level [4]. Since at the initiating of primary health care centers (PHCCs) services in Iraq, many studies have been conducted to evaluate different clinical and administrative aspects of PHCC activities [5,6]. However, very few studies have been undertaken to assess the level of satisfaction among PHCWs [7].

\section{Subjects and method}

A cross sectional survey was conducted in Health Directorate of Holy Karbala Governorate, Iraq. A total 572 of health providers a self-administered questionnaire on factors associated with job satisfaction, Were included in this study. The data collection carried out for a period of five months from January 2, 2017 to the end of May 2017. Data collected by direct interview with health providers involved all health providers worked in PHCCs that included (Doctors, dentists, Pharmacies and Paramedical staff). Using a questionnaire form that 
designed based on the study objectives, it administered to the participants and the results consolidated and the statistical package for social sciences (SPSS) software version 18 was use for data analysis. The statistical significance represented if a p-value of less than 0.05 .

\section{Results and Discussion:}

Many studies handled provider satisfaction specially for physicians ,in Iraq [8], While other study for patient in Saudi Arabia [9 ,10,11] , and in Kuwait by Alhashem, A., H. Alquraini and R. Chowdhury[12,13], and in all reviewed articles, dissatisfaction was inferred, Two articles tackled identified 'practice pressure' as the factor behind dissatisfaction $[14,15]$. Practice pressure included time pressure, patient overload and inadequate support. The third study discussed the unrecognized professional identity that midwives face at work [16].

While researchers don't found study among health providers, Health providers as workers in health situation and more knowledge and awareness about health services in hospital and primary healthcare centers, Therefore selected the healthcare workers as study sample to conduce this paper. Across section study conducted in holy karbala governorate among a sample of health providers to assessment satisfaction of primary health care services provided from health institution.

Five hundred and seventy-two of six hundred questionnaires were returning, a response rate of 95.4 $\%$.Our study involved all health providers worked in PHCC that included (Doctors, dentists, Pharmacies and Paramedical staff).

The distribution health providers according to the demographic characteristics. There was a distinct male's preponderance ( $65.4 \%$ ) with (mean $\pm \mathrm{SD}$ of their ages were $36.8 \pm 9.8$ years), the age range at the time of study were between (21-60) years, ( male : female ratio was 1.3:1) and the highest percentage (35.7\%) were in the age group $(\leq 30)$ years, while regarding residency most cases $(58.7 \%)$ from urban area, regarding the distribution of the health providers as educational level high percentage about (50\%) were had College and more, and regarding Occupation the research involved all title of health care workers worked as staff in primary health care centers therefore; more than half of studied sample $(57.9 \%)$ were Paramedical staff.

Table (1): The distribution of studied sample according to the demographic characteristics

\begin{tabular}{|c|c|c|c|}
\hline \multicolumn{2}{|c|}{ Categories } & No. & $\%$ \\
\hline \multirow{2}{*}{ Gender } & Male & 374 & 65.4 \\
\hline & Female & 198 & 34.6 \\
\hline \multirow{4}{*}{ Age group } & $\leq 30$ & 204 & 35.7 \\
\hline & $31-40$ & 180 & 31.5 \\
\hline & $41-50$ & 160 & 28.0 \\
\hline & $\geq 51$ & 28 & 4.9 \\
\hline \multirow{2}{*}{ Residency } & Urban & 336 & 58.7 \\
\hline & Rural & 236 & 41.3 \\
\hline \multirow{3}{*}{ Education level } & secondary & 132 & 23.1 \\
\hline & health diploma & 156 & 27.3 \\
\hline & College and more & 284 & 49.7 \\
\hline \multirow{4}{*}{ Occupation } & Doctor & 94 & 16.4 \\
\hline & dentist & 82 & 14.3 \\
\hline & Pharmacy & 65 & 11.4 \\
\hline & Paramedical staff & 331 & 57.9 \\
\hline \multicolumn{2}{|c|}{ Total } & 572 & 100.0 \\
\hline
\end{tabular}


Regarding Your jobs satisfaction, the majority (63.1\%) of health provider considered the health services satisfy, this result conforms to that reported in a study conducted in Erbil, Kurdistan, Iraq, which founded a job satisfaction rate of 33.3\% [7]. And all of them reflected health services Coverage remote areas and there are significant association ( $P$. value 0.001), This is a same rate if compared with other studies carried out in neighboring countries that have similar socio-economic characteristics, such as; Kuwait $61.8 \%$, Saudi Arabia

$47.6 \%$, Iran 59\%,Turkey $60 \%[13,10,11,12]$, and in other countries like UK and New Zeeland the rate was even higher $[14,15]$. this evaluation may be was as a result of disseminate of primary health care centers (PHCCs) and medical house in every part of governorate, while $(38.5 \%),(67.3 \%)$ deliberated the health services mad up good health education and there are significant association (P. value 0.002) and Continuous services while there are no significant association $(\mathrm{P}$. value $>0.05)$ respectively table $(2)$. That may be due to the primary health care center services (PHCCS) considered simple services and very easy available to civilization as all the year.

Table (2): The distribution of studied sample according to services satisfy people needs

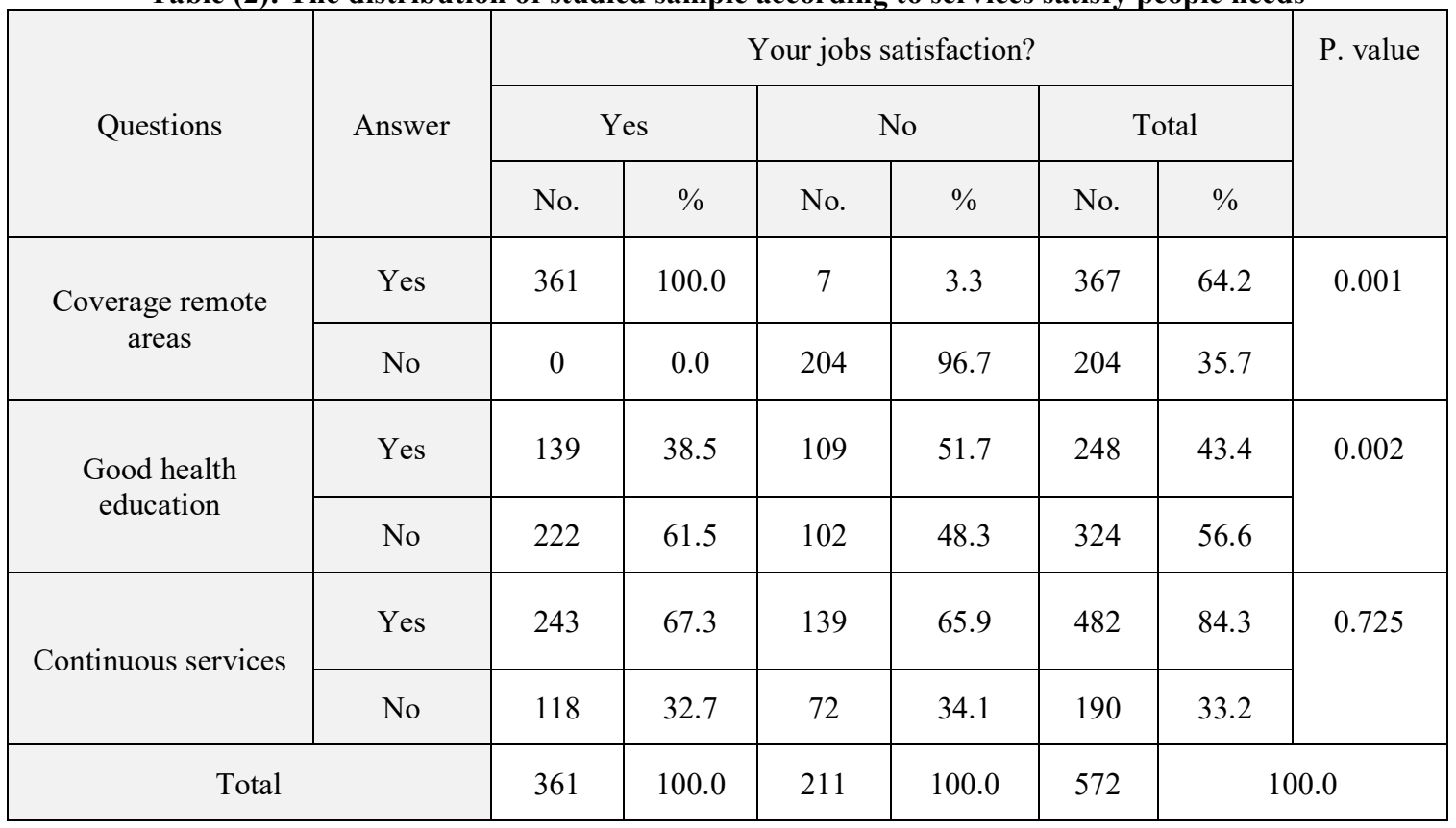

Regarding doctor give enough time for each client, the majority (63.8\%) of health provider don't accepted ,the same result found in a study done by Ahmed et al., 2014 in Iraq[63], who revealed that the satisfaction decreases significantly as the number of the patients increases $(\mathrm{P}=013)$.

Approximately two-thirds of the sample (66.4\%) indicated that, due to the number of patients that they see, there is too little time for preventive medicine during consultations. The same number of respondents $(66.4 \%)$ felt they did not have time to satisfy their social commitments. and $(22.9 \%)$ of them reflected Lack of that may as a result to limited types of drugs that available because the lackey of health finical and there are no significant association (P. value 0.702$)$, while $(31.1 \%),(17.5 \%),(6.1 \%)$ and $(26.9 \%)$ of health provider represented (too much patients, Insufficient staff, Doctors busy with health program statistics and Doctors busy in administrative work) respectively, as causes for doctors don't give enough time for each client and there are significant association (P. value 0.001 ) that clear at table (3). 
Table (3): The distribution of studied sample according to doctor give enough time for each client

\begin{tabular}{|c|c|c|c|c|c|c|c|c|}
\hline \multirow{3}{*}{ Questions } & \multirow{3}{*}{ Answer } & \multicolumn{7}{|c|}{ Does doctor give enough time for each client? } \\
\hline & & \multicolumn{2}{|c|}{ Yes } & \multicolumn{2}{|c|}{ No } & \multicolumn{2}{|c|}{ Total } & \multirow{2}{*}{$P$.value } \\
\hline & & No. & $\%$ & No. & $\%$ & No. & $\%$ & \\
\hline \multirow{2}{*}{ Lack of Medication } & Yes & 71 & 12.4 & 131 & 22.9 & 202 & 35.3 & \multirow{2}{*}{0.702} \\
\hline & No & 136 & 23.8 & 234 & 40.9 & 370 & 64.7 & \\
\hline \multirow{2}{*}{ Too much patients } & Yes & 207 & 36.2 & 178 & 31.1 & 385 & 67.3 & \multirow{2}{*}{0.001} \\
\hline & No & 0 & 0.0 & 187 & 32.7 & 187 & 32.7 & \\
\hline \multirow{2}{*}{ Insufficient staff } & Yes & 120 & 21.0 & 100 & 17.5 & 220 & 38.5 & \multirow{2}{*}{0.001} \\
\hline & No & 87 & 15.2 & 265 & 46.3 & 352 & 61.5 & \\
\hline \multirow{2}{*}{$\begin{array}{l}\text { Doctors busy with health } \\
\text { program statistics }\end{array}$} & Yes & 45 & 7.9 & 35 & 6.1 & 80 & 14.0 & \multirow{2}{*}{0.001} \\
\hline & No & 162 & 28.3 & 330 & 57.7 & 492 & 86.0 & \\
\hline \multirow{2}{*}{$\begin{array}{c}\text { Doctors busy in administrative } \\
\text { work }\end{array}$} & Yes & 122 & 21.3 & 154 & 26.9 & 276 & 48.3 & \multirow{3}{*}{0.001} \\
\hline & No & 85 & 14.9 & 211 & 36.9 & 296 & 51.7 & \\
\hline \multicolumn{2}{|l|}{ Total } & 207 & 36.2 & 365 & 63.8 & 572 & 100.0 & \\
\hline
\end{tabular}

In $40 \%$ of health providers questioned, the afternoon work is medical (either in people's clinic or in private clinics). Not surprising, $56.0 \%$ of health providers have an afternoon work. The remaining of providers seems to be satisfied with the governmental work only (Fig 1).

\section{Afternoon Work}

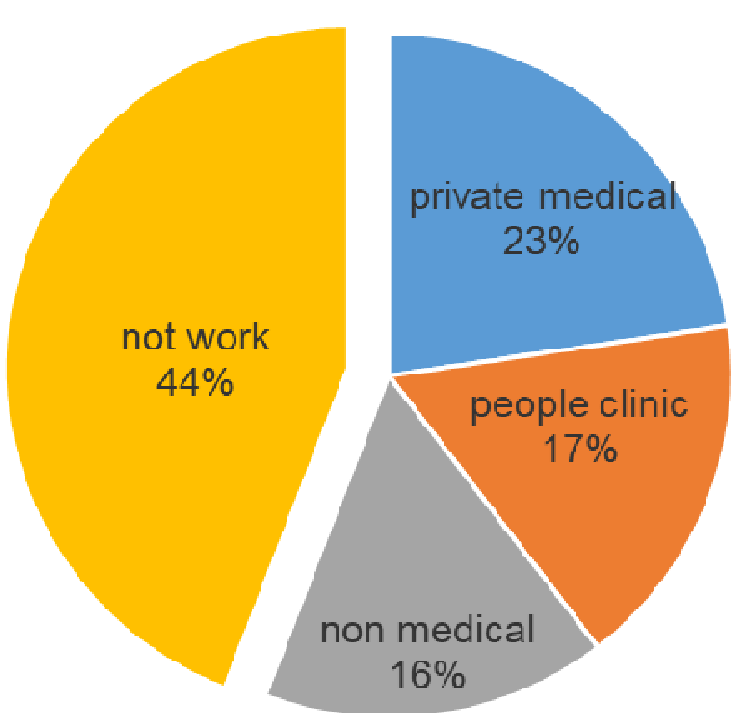

Fig( 1): Afternoon work category of health providers

Sixty-seven percent of health providers prefer the application of a family health care system and Forty- 
three percent of health providers agree that an application of a social (health) insurance system is need. There is a highly significant relation between opinions of health providers on family care and social insurance systems $(\mathrm{p}$. value $=0.001)($ table 4$)$.this result may be due to increase needing of the community to health services and increase the diseases that effecting the people such as heredity and cancers diseases specially at last 10 years, therefore this system will be available enough information to a family doctor about health problem of family and expecting the future disease and how can preventing and treating of it, the researchers don't found any study about Health (social) insurance system and family health care system that may be due to this system conducted in the majority status of world.

Table (4): Health providers' opinions on application of Health (social) insurance system and family health care system

\begin{tabular}{|c|c|c|c|c|c|c|c|c|}
\hline & \multirow{3}{*}{ Question's } & \multicolumn{6}{|c|}{$\begin{array}{r}\text { o you agree with health insurance, in which each family } \\
\text { pays a monthly fee (according to its ability) for } \\
\text { getting most health services free? }\end{array}$} & \multirow{3}{*}{ p. value } \\
\hline & & & Agree & & agree & & Total & \\
\hline & & No. & $\%$ & No. & $\%$ & No. & $\%$ & \\
\hline \multirow{2}{*}{$\begin{array}{l}\text { Do you agree with having a family } \\
\text { doctor for each area responsible for } \\
\text { family members' health, and can be } \\
\text { contacted or visited in afternoon? }\end{array}$} & Agree & 383 & 67.0 & 19 & 3.3 & 402 & 70.3 & \multirow{2}{*}{0.0001} \\
\hline & disagree & 46 & 8.0 & 124 & 21.7 & 170 & 29.7 & \\
\hline \multirow[b]{2}{*}{$\begin{array}{l}\text { Do you agree with prevent mix } \\
\text { of private and governmental work, i.e. } \\
\text { the doctor or pharmacist works either } \\
\text { with the government or in private? }\end{array}$} & Agree & 246 & 43.0 & 22 & 3.8 & 268 & 46.9 & \multirow{3}{*}{0.0001} \\
\hline & disagree & 183 & 32.0 & 121 & 21.2 & 304 & 53.1 & \\
\hline & Total & 429 & 75.0 & 143 & 25.0 & 572 & 100.0 & \\
\hline
\end{tabular}

\section{Acknowledgements}

Sincere thanks are extended to all staff members of community health technologies department in holy Karbala Governorate for their assistance and encouragement and I am sincerely highly grateful and indebted to Assist. Prof. Dr. Salim Hussein Hasan head of department

I must express my heart full gratitude to all medical and paramedical staff their participation and cooperation in this study.

I don't know how to express my thanks \& appreciation to all those who have in one way or another supported, facilitated and contribute in my study, Special appreciation is given to: My parents, my dearest wife, sons, my brothers and my sisters Your love, encouragement made it possible for me to complete my study, thank you very much, I love you. God bless you All.

\section{$\underline{\text { References }}$}

1. Locke EA. What is Job Satisfaction, Organ Behav Hum Perf 1969; 4: 309-36.

2. Smith PC, Kendall LM, Hulin CL. The Measurement of Satisfaction in Work and Retirement. Rand McNally, USA 1975; pp. 5-20.

3. Robbins SP. Organizational Behavior: Concepts, Controversies, and Applications. 9th ed. Prentice-Hall, Englewood Cliffs 2000; 139-43.

4. Carmen G, Sandra R, Isabel R, Onofre M. Family Physician Job Satisfaction in different medical care organization models. Family Practice 2000; 17(4): 309-13. 
5. Khudhairi JM. Evaluation of primary healthcare system as a prerequisite for Iraqi health system reform. $\mathrm{PhD}$ thesis. Al-Mustansiriya University ,2005.

6. Shabila NP, Al-Tawil NG, Al-Hadithi TS, Sondorp E. A qualitative assessment of the Iraqi primary healthcare system. World Health Popul. 2012; 13(3): 18-27.

7. Wali O, Khales B, Samir M. Job Satisfaction among Primary Health Care Physicians in Erbil City. Iraqi Medical Journal, 2010; 56(2): 146-50.

8. Ahmed et al.: Job Satisfaction among Primary Health Care Physicians in Al-Karkh district, Baghdad, Mustansiriya Medical Jo urnal, Volume 13 Issue 1 June 2014,65-69.

9. Alia Almoajel, Ebtisam Fetohi and Amani Alshamrani, Patient Satisfaction with Primary Health Care in Jubail City, Saudi Arabia, World Journal of Medical Sciences, 2014, 11 (2): 255-264

10. Banakhar, Al-Khafee, Fllatah, Al-Abdul Aziz, Al-Shibily and Al-Amri,. Patient Satisfaction of Primary Health Care Service,2006. Available:http://www.kau.edu.sa/Files/0007633/Researches/36969_Patient_satisfaction_ in_ primary_ health_care_center_service.

11. Al-Qatari GM, Haran D. Determinants of satisfaction with primary health care settings and services among patients visiting primary health care centres in Qateef, Eastern Saudi Arabia. Middle East J Fam Med, 2008; 6:3-7.

12. Alhashem, A., H. Alquraini and R. Chowdhury. Factors influencing patient satisfaction in primary healthcare clinics in Kuwait. International Journal of Health Care Quality Assurance, 2011. 24(3): 249-262.

13. Al-Eisa IS, Al-Mutar MS, Radwan MM, Al-Terkit AM. Patients' satisfaction with primary health care services at capital health region, Kuwait. Middle East J Fam Med, 2005; 3: 277-300.

14. Al-Qutob R, Nasir LS. Provider perceptions of reproductive health service quality in Jordanian public community health centers. Health Care Women Int, 2008;29:539-50.

15. Al Marri SA, Al Taweel AA, Elgar FJ. Factors influencing job satisfaction among primary health care physicians in Qatar. Qatar Med J 2002;11:15-18.

16. Shaban I, Barclay L, Lock L et al. Barriers to developing midwifery as a primary health-care strategy: a Jordanian study. Midwifery, 2012;28:106-11.

17. Al-Eisa I, Al-Mutar M, Al-Abduljalil H. Job satisfaction of primary health care physicians at capital health region, Kuwait. Middle East Journal of Family Medicine ,2005; 3(3): 23-8.

18. Al Juhani A, Kishk N. Job satisfaction among primary health care physicians and nurses in Al- Madinah A1Munawwara. Journal of the Egyptian Public Health Association ,2006; 81(3): 165-80.

19. Arab M, Pourreza A, Akbari F, Ramesh N, Aghlmand S. Job satisfaction on primary health care providers in the rural settings in Iran. Iranian Journal of Public Health, 2007; 36(3): 64-70.

20. Bodur S. Job satisfaction of health care staff employed at health centres in Turkey,Occupational Medicine, 2002; 52(6): 353-5.

21. Dowell A, Hamilton S, McLeod D. Job satisfaction, psychological morbidity and job stress among New Zealand general practitioners. New Zealand Medical Journal, 2000; 6: 269-72.

22. Branthwaite A, Ross A. Satisfaction and job stress in general practice, Journal of Family Practice, 1988; 5: 83-93.

23. Ahmed et al.: Job Satisfaction among Primary Health Care Physicians, Mustansiriya Medical Journal, 2014, Volume 13 ,Issue 1, June, 65-70. 